Authors copy (published in 2020 in Sports, Ethics \& Philosophy)

https://doi.org/10.1080/17511321.2020.1770846

\title{
Would relaxation of the anti-doping rule lead to Red Queen effects?
}

Bengt Kayser ${ }^{1}$ and Andreas de Block ${ }^{2}$

${ }^{1}$ Institute of sport sciences, University of Lausanne, Switzerland.

bengt.kayser@unil.ch; orcid.org/0000-0002-9776-7501

${ }^{2}$ Institute of philosophy, University of Leuven, Belgium

andreas.deblock@kuleuven.be

Correspondence: Bengt Kayser, ISSUL, Synathlon, Uni-Centre, 1015 Lausanne, Switzerland 


\begin{abstract}
One of the claims sometimes advanced in favour of anti-doping is that allowing doping would lead to a uniform increase in performance in comparison to no doping. The idea is that if all athletes would use doping, this would just shift the playing field to a higher level without a change in ranking, but at a higher health cost. In this paper, we critique this contention. We first develop our theoretical framework, with reference to the so-called Red Queen effect. We then argue that, if doping were allowed, Red Queen effects would not be the rule. We also show that to some extent Red Queen effects would occur, but these would not necessarily be morally problematic. We end by developing an argument in favour of a more liberal approach of doping, since such would allow escaping from today's runaway effects of anti-doping efforts.
\end{abstract}

Keywords: doping, anti-doping, sport, drugs, policy

Wordcount: main text 6027, abstract 143

\title{
Introduction
}

Doping is vilified mainly because considered an unfair distortion of the playing field and a threat to the athlete's health. Despite increasingly repressive anti-doping efforts under the guidance of the world anti-doping agency (WADA) doping remains prevalent in elite sport. According to WADA, based on adverse analytical findings (i.e. presence in urine or blood of forbidden substances), 1-2\% of elite athletes use doping. Indirect evidence suggests that actual prevalence is much higher, ten times or even more, depending on the method of measurement and varying between sports and countries (Faiss et al., 2020; Hon et al., 2015; Petróczi et al., 2008; Ulrich et al., 2017). Anti-doping thus does not attain its goal of eradication of doping, despite far-reaching - and sometimes morally problematic surveillance of athletes who have to report their $24 \mathrm{hr}$ whereabouts all-year round to allow unannounced urine collection by doping officers who visually identify the correct anatomical origin of the sample. Furthermore, up to $40 \%$ of athletes with a documented adverse analytical finding (the $1-2 \%$ of those tested) may not have intended to dope (Hon et al., 2015) and there are regular accounts of unlucky innocent athletes being sacrificed for the sake of 
'clean’ sport (Dimeo \& Møller, 2018; Moston \& Engelberg, 2016; Pluim, 2008). Anti-doping calls for additional resources for more stringent repression along an end-justifies-the-means prohibitionist discourse. Critical analysis of the arguments in favour of current anti-doping policies is therefore warranted since it may provide insight for developing alternative ways of dealing with doping in sport.

The ethics of doping and anti-doping remain vividly debated (Brown, 1980; Dixon, 2008; Loland, 2009; Schneider \& Butcher, 1993; Simon, 1984). The aim of the present paper is to single out one specific aspect and discuss it in more detail, thereby necessarily leaving aside many other important points. This aspect is that many stakeholders, such as athletes and spectators, but also pundits and scholars argue that allowing doping would eventually lead to a uniform increase in performance in comparison to no doping (Chwang, 2012; Martins, 2018). The idea is that if all athletes would use doping, this would just shift the playing field to a higher level without a change in ranking. This would however come at a higher health cost, because of health risks of some forms of doping. The objective of this paper is to formulate our critique of this contention. We do this by first presenting our theoretical framework, with reference to the so-called Red Queen effect. We then show that Red Queen effects would not be the rule if the anti-doping rule would be relaxed. Moreover, to the extent, that some Red Queen effects could still be expected to occur, we think they would not necessarily be morally problematic. We then go on by showing that the absence of a Red Queen effect has normative consequences. We conclude by arguing in favour of a more liberal approach of doping, since such would allow escaping from today's runaway effects of anti-doping efforts.

\section{Red Queen effects}

In Lewis Carroll's 'Through the Looking Glass, and What Alice Found There', Alice and the Red Queen are running very fast but there is no change in their position relative to their environment. "Now, here, you see, it takes all the running you can do, to keep in the same place" [original emphasis], is the answer of the Red Queen to panting Alice's observation of their apparent stasis, in spite of her intense physical effort (Carroll, 1871). In 1973, evolutionary biologist Leigh Van Valen used the Red Queen's race as a metaphor to make sense of his observation that the fossil records showed constant extinction rates for subtaxa of a large number of taxa (Valen, 1973). Van Valen coined the Red Queen effect for the co- 
evolutionary process in which the benefits of a new and costly adaptation of one species (S1) are in parallel offset by new and costly adaptations developed by that species' ecological predator, prey, host, parasite or competitor (S2), in response to the adaptations of S1. For example, when S1 got faster, S2 also became faster, leading to escalation and loss of ecological balance, pushing the two species towards extinction. In other words, both species would have been better off if they had not been caught up in such an evolutionary arms race. Evolutionary biology now uses the Red Queen effect to describe both inter- and intra-species runaway dynamics. As an example of the latter one can think of the increasing size of antlers in male deer, a costly male adaptation for competition for reproduction with females, that may have played a role in the extinction of the 'Irish Elk' whose palmate antlers had increased up to a span of $3.6 \mathrm{~m}$ (Worman \& Kimbrell, 2008).

Van Valen originally conceptualized the Red Queen effect as a macro-evolutionary trend to explain a general pattern in biological evolution. Soon, others used the Red Queen dynamics that Van Valen had sketched to explain escalation patterns on much shorter time scales. For example, it was argued that humans developed specialized cheater detection mechanisms in response to the development of sophisticated cheating mechanisms among their peers (Cosmides \& Tooby, 2008). The Red Queen effect has also been used to account for similar dynamics outside the context of evolutionary biology. For instance, Gali (1994) has argued that conspicuous consumption is best explained as a Red Queen effect: people consume conspicuous goods in order to 'keep up with the Joneses'. In the end, nobody improves their relative social rank, while everybody spends a lot of resources on things one does not need such as swimming pools, huge outdoor kitchens or SUVs. In The Economic Naturalist, Robert Frank suggests that the costs of such dynamics are not just financial, but can involve health costs as well (Frank, 2007). For example, some women may wear high heels to grab the attention of men, but when many women go along with this, at least part of the aesthetic advantage of wearing high heels is lost, while knee and ankle problems increase (Dawson et al., 2002).

Although the term 'Red Queen effect' is not often used in debates on doping, the concept is (Danaher, 2012; Shermer, 2008). It is often argued and even more generally believed, for instance by many of the undergraduate students we have taught, that if doping were allowed, all athletes would consider doping as a requirement for their success in sport. Ubiquitous 
doping and escalating doping use would then result in an invariant overall ranking, while morbidity and mortality would increase because of doping's harmful side-effects. Chwang (Chwang, 2012) coined this a 'positional treadmill' effect and assumed its validity for his argument in favour of anti-doping. If one would allow doping, athletes would either start using doping or drop out. In that sense, all elite athletes wanting to compete would be obliged to use doping. Our main concern here is not with how engaging in doping can be seen as a prisoner's dilemma. Rather, we are interested in two special characteristics of the doping related prisoner's dilemma that some anti-doping advocates highlight. The first characteristic is that everybody would be better off if no-one used doping (Breivik, 1992; Chwang, 2012). The second characteristic is that an escalated use can be expected as soon as doping use is allowed. Our argument rests on the debunking of several assumptions that underlie the antidoping advocates' fear for dramatic Red Queen effects in sports if doping were allowed. In the first section, we will address the idea that it's in everybody's best interest to ban doping. We think there are good reasons to think that in general at least someone is better off if a substantial number of athletes or even every athlete would be doping. The ubiquity of interaction effects makes it unlikely that the athletic value ratio between two athletes will remain identical before and after the doping use.

\section{Interactions}

Our argument rests on the debunking of the assumption that allowing everyone to use doping would not change anything sport-relevant, because of a uniform upward shift of the playing field. One way of tackling this contention, is by arguing against the view that a uniform upward shift would not add anything to sports. For instance, one could argue that even if the ranking would remain unchanged if every athlete used doping, some aesthetic properties of the performance or the game would still be different (more or less aesthetically pleasing). This is not the angle we will take. The reason is that we think the empirical premise is just incorrect: if all current athletes would start doping, the future ranking in their sports would be affected. The assumption that the effect of a given doping technology is the same for all is flawed, as we show hereunder. We discuss what is known about the determinants of elite performance and interventions other than doping such as training on performance enhancement and then show that similar non-uniform patterns can be expected for doping. 
The exercise-physiologist Per-Olof Åstrand allegedly once quipped that in order to become an Olympic athlete one should choose one's parents wisely. Talent has a high heritability and a good potential for elite excellence can, on the condition of exposure to the right environment, be transformed into optimal performance, increasing one's chances in elite competition (Baker \& Wattie, 2018; Issurin, 2017; Moran \& Pitsiladis, 2016; Sanchis-Gomar et al., 2016; Tucker \& Collins, 2012).

In the discussion of potential Red Queen effects in doping dynamics one should take into account the extent of inter-individual variation in this interaction between a given genetic endowment and a particular environment. Talent is to some extent heritable and hence unevenly distributed. Take aerobic capacity, a prime determinant of endurance performance. The greater the aerobic capacity, the greater the sustainable metabolic rate, the greater the energy available for muscle contraction and hence the greater the potential for endurance performance. In the Family Heritage Study, Claude Bouchard and colleagues studied the role of genotype in the cardiorespiratory and metabolic responses to aerobic exercise training (Bouchard et al., 1999). 742 healthy sedentary subjects with varying degrees of kinship, 17 to 65 years old, were tested, exercise-trained in the laboratory under supervision with the same program for 20 weeks, and re-tested. The response to endurance training was found to be $\sim 50 \%$ heritable. While the average increase in aerobic capacity for an identical training stimulus was $19 \%$, about $5 \%$ of the subjects had little or no change $(<5 \%)$ while about $5 \%$ had an increase of $40 \%$, and some even saw their aerobic capacity increase with more than $50 \% .29$ genes predicted training response and 11 particular SNPs (single nucleotide polymorphism, a signature of genetic difference for a given gene between individuals of a species) captured $50 \%$ of the estimated variance attributable to genetic differences (Timmons et al., 2010). Not only the response to training, but also responses from interventions such as nutritional strategies vary importantly between individuals because of their genetic make-up (Baar, 2014; Joyner \& Lundby, 2018; Pigeyre et al., 2016).

Another illustration of different responses between athletes to a given intervention is altitude training, a common practice among endurance athletes. The underlying rationale is the following. The lack of oxygen from the thinning air at altitude induces low blood oxygen levels. These stimulate the production of erythropoietin (EPO), a hormone which drives the production of new red blood cells. These increase the oxygen-carrying capacity of the blood, a main determinant of aerobic capacity, and therefore endurance performance upon descent to 
low altitude. However, there is important individual variation in the effects of an identical altitude exposure [responders and non-responders, (Millet et al., 2019; Siebenmann et al., 2012; Sinex \& Chapman, 2015)]. It is unknown what the underlying mechanisms are, but they are likely genetic. Instead of using altitude exposure to stimulate the organism's EPO production, EPO can also be injected. When EPO appeared on the market, endurance athletes were quick to adopt its use, because it circumvented the complexity of altitude training. Again it was observed that the effects of EPO not only varied with dosage but also among individuals, and a debate on its effectiveness for elite performance is still ongoing (Clark et al., 2017; Hardeman et al., 2014; Heuberger et al., 2013). EPO is not the only substance with different effects between persons. In fact, it is true for many pharmaceuticals that some respond well to them and some do not respond, some will experience no side-effects and some will develop very strong side-effects.

These interactions are so important that a separate field has emerged that studies how drugs affect individuals differently because of their particular genetic make-up. This field is called pharmacogenomics and the goods it will deliver encompass the possibility to individually tailor more effective and safer medication strategies. This burgeoning scientific field also holds promise for the development of personalized medicine approaches in order to adapt choice and dosage of pharmacology to the individual genotype and phenotype (Filipski et al., 2016). There is all reason to expect that such variation in effects also applies to most doping substances, and even that performance-relevant three-way interactions between doping substances, training intensity and genes are not rare. In other words, it is naïve to assume that doping use by all elite athletes would not affect the ranking. In part because of the important interaction effects we underscored in this section, it is also naïve to think that allowing doping necessarily leads to an escalated use of doping. We will further develop this issue in the next section.

\section{Escalation}

The next assumption we address is that allowing doping would lead to a true arms race in which every athlete would dangerously escalate their use of substances so as to incur significant health risk. We present two arguments that question this assumption. We first make a distinction between escalations of amount and escalations of risk, and then question the use of game theory to predict that what has not yet come, a runaway catastrophe. 
Some anti-doping proponents argue or assume that a liberal doping policy would lead to runaway effects of dosage since more is believed to be better. For any pharmacological substance there are three questions that need to be answered: What is the magnitude of effects (beneficial or adverse) from a given dose? How quickly will any given effects occur? And how long will these effects last? (Wright et al., 2011) For any substance used for performance enhancement the answers to these questions vary according to the specific pharmacology (kinetics and dynamics) of the substance and the physiology of the user. Importantly, the effects of a substance do not scale linearly with its dosage (Wright et al., 2011). To enhance one's performance, an optimal dose of a drug needs to be taken. Importantly, the optimal dose is not necessarily a high dose. In some cases, the dose can even be relatively low. Because the poison is in the dose, this also entails that coincidence between the best performance enhancement effect and lethal risk is far from necessary and quite often simply unlikely. For example, in precision sports such as shooting, archery and biathlon tremor can be controlled and shooting performance improved with a beta-blocker dosage that remains below lethal because of the ergolytic effects of increasing dose (Kruse et al., 1986). Caffeine improves exercise performance in a broad range of exercise tasks at dosages much below lethal ones (Grgic et al., 2019). Sure, excessive intake of about anything is dangerous and even water can be deadly when consumed in excess and actually is, when slow marathon runners take the sports drink industry's marketing slogan 'drink before you are thirsty' too literally and subsequently develop hyponatraemia leading to sometimes lethal brain oedema (Hew-Butler et al., 2017). It thus follows that the argument of escalation of amount simply because more is better does not hold.

The second part of the escalation argument states that athletes are prone to taking more than a reasonable amount of a doping substance. They therefore risk significant health harm and should be protected from themselves. To bolster this argument the anti-doping literature frequently cites the so-called Goldman dilemma. It states that a majority of athletes is willing to ingest a magic pill if it could make them an Olympic champion, even if it would kill them in 5 years (Goldman \& Klatz, 1992). Christiansen and Møller (Christiansen \& Møller, 2007) tried to find the original research by Mirkin, cited in Goldman's book, and concluded that the study was probably never formally conducted. Since then, several published studies have rejected Goldman's claims (Connor \& Mazanov, 2009; Connor et al., 2013). There is therefore no reason to believe the dramatic postulate of Mirkin and Goldman. There is also no 
good epidemiological evidence for excessive morbidity and mortality before the advent of modern anti-doping, when doping was supposedly frequent, for example in professional cycling. Individual cases such as that of the death of Knud Enemark Jensen in the Rome Olympics of 1960 and that of Tom Simpson during the 1967 Tour de France are repeatedly cited as proof, even though the role of doping in their deaths remains unclear (López, 2013; Møller, 2005). Overall, there is no indication of excess morbidity or mortality among athletes in the heyday of doping with an exception for state-imposed doping of - especially female athletes with anabolic steroids in East-Germany (Dimeo \& Hunt, 2012; Franke \& Berendonk, 1997). In contrast, there is good evidence that longevity is better among former Olympians and Tour de France cyclists (Teramoto and Bungum 2010; Marijon et al. 2013; Clarke et al. 2015). The anti-doping discourse frequently predicts catastrophe if doping were allowed. According to historian Lopez such anti-doping discourse is an example of fear mongering at the service of a social control and surveillance agenda. He argues that the evidence base for doping's excessive dangerousness is often shallow (López, 2013, 2016).

Of course, we do not want to deny that many pharmacological substances come with potentially very dangerous side effects. For many substances, if taken in excess or taken in inappropriate ways, the health risks are real. For example, excessive use of over-the-counter anti-inflammatory drugs by athletes (and by the general public, for that matter) can have very harmful side-effects (Warden, 2015), and non-medically supervised use of anabolic steroids, for example by body-builders, can lead to major health problems (Karila et al., 2003; McVeigh \& Begley, 2016). However, when considering doping substances the risks are often exaggerated especially in comparison to other risks people partake in on a daily basis.

Other arguments for the risk of escalation in doping use build upon game theoretical approaches and insights (Breivik, 1992; Shermer, 2008; Strulik, 2012). Van Valen already thought of the Red Queen effect in terms of game theory, with each species taking part in a zero-sum game against the other species in which no species can ever win, and where new adversaries 'grinningly replace the losers' (Valen, 1973). Applied to doping the simplest game theory scenario is as follows. If athlete A refrains from doping, then athlete B will gain an advantage by doping. If athlete $A$ uses doping, it is also in the interest of athlete $B$ to use doping, to try and keep up. It follows that since B does not know for sure what athlete A is doing, it is a better idea to use doping than not to. The same reasoning accounts for athlete A and the end-result tends therefore towards pervasive doping. Here, doping use is the strategy 
of a rational athlete confronted with a simple prisoner's dilemma. The Red Queen effect thus occurs where defecting is not just the rational choice, but where ever more defecting is rational and escalation towards ever more doping would thus be expected. This shift, towards doing what the other is suspected to be doing to improve performance, is not uncommon; the same mechanism is at work for other means used to gain an edge over the opponent, such as better exploiting the possibilities of training, nutrition, material, etc.

Chwang for example, also uses a game theoretical approach in his plea in favour of antidoping. He starts from the premise that doping is harmful to dopers (Chwang, 2012). Reasoning that allowing doping would shift the playing field uniformly up if all athletes engaged in doping (prisoner's dilemma) he then posits that athletes would prefer not to dope because of its harm and lack of a competitive advantage (Red Queen effect). An impartiality premise then states that one should not allow some athletes to dope but not others. A beneficence premise, that we should give athletes what they want (i.e. a preference for no doping), then leads Chwang to conclude that one should therefore ban doping (Chwang, 2012).

We already demonstrated that the premise of a uniform shift of the playing field is flawed and that Red Queen effects would not be the rule when doping were allowed. Equally important is that we have serious doubts that the game theoretical models adequately predict the behaviour of athletes. Game theoretical models attempting to explain or predict doping behaviour cannot be tested against empirical data because of the covert nature of the behaviour and for fear of catastrophe if doping were allowed. However, the literature on the psychology and sociology of doping suggests a rich pattern of factors influencing doping behaviour where rational choice is not the rule (Elbe \& Barkoukis, 2017; Ring et al., 2017; Smith, 2016). More generally, human decision-making exhibits a suite of biases when making economic decisions. For example, it is not uncommon to take (unreasonable) long term risk for short term return (Jolls et al., 1998), a bias that has probably evolved in our lineage, like many similar biases (Santos \& Rosati, 2015). Likewise, although the most rational strategy in a 'war of attrition'-like auction is to bid more than the value of the product that one is bidding for, people are never willing to pay a million dollars for a dollar in a so-called dollar auction, even that is what they would end up doing if they made all rational choices (Teger, 2017). Given the complex determinants of human behaviour, it is therefore difficult to predict what would 
happen under a liberal doping policy, and game theory will often generate the wrong predictions. Or, as game theorist and economist Ariel Rubinstein put it:

\author{
There are those who believe that the goal of game theory is ultimately to \\ provide a good prediction of behaviour in strategic situations [...]. I am not \\ sure on what this vision is based. Most situations can be analysed in a \\ number of ways, which usually yield contradictory 'predictions'.
}

(Rubinstein, 2007)

We acknowledge that due to the extreme stakes in elite sports, some athletes would decide to use substances in excess of reasonable health risks if doping were allowed, similarly to the important other health risks related to their sport that athletes are willing to take. But optimising doping use, i.e. exploiting its performance enhancing effects while balancing this with the potential health risks, is not the same as escalation of amount of doping use. Even if game theory would suggest the potential for escalation of health risk from escalation of doping use, this is not necessarily the case, as illustrated by what was the situation before the advent of modern anti-doping. We therefore conclude that pervasive escalation of dosage among athletes would not be the rule, although we do acknowledge that some athletes and support personnel might incorrectly believe that more is always better and would be willing to take excessive risk.

So far our reasoning has concerned doping substances considered to be objectively dangerous. Athletes and the public at large mostly assume that substances on WADA's 'Prohibited List' are both performance enhancing and dangerous. But WADA does not communicate the reasons for adding a particular substance to its List. As is well-known, three criteria are used of which at least two have to be met: 1) enhancing, or having the potential to enhance, performance; 2) posing an actual or potential health risk; and 3) being contrary to the 'spirit of sport'. Apart from its catch-all approach due to the inclusion of 'the spirit of sport', it is clear that for many substances on the List there is no good evidence that they enhance performance or cause harm (Heuberger \& Cohen, 2019). The List contains substances for which dangerousness can be considered acceptable or even absent, even though the adage 'the dose makes the poison' remains correct (even water can be deadly when taken in excess). The ban on doping and WADA's decision process on the List maintain general ignorance, with unintended but potentially harmful effects (Fincoeur et al., 2013; Milot, 2014). For instance, 
athletes may take illicit substances that actually do not enhance performance but might cause harm, while licit substances such as NSAIDS (e.g. paracetamol, ibobrufen) are frequently used by athletes, for which the balance between the therapeutic effect, performance enhancement and harm from side-effects are not clear (Warden, 2015).

In the context of escalation, it is important to note that the List includes non-harmful substances besides genuinely harmful substances. Take meldonium, for which in healthy individuals there is not only no evidence for improvement of performance but also no evidence of a relevant health risk (Negro et al., 2018). Or take aromatase inhibitors such as exemestane, which lead to a modest increase in testosterone with little side-effects (Lintermans et al., 2011). This entails that even if the use of these substances escalates, the negative health effects of the escalation may sometimes be less than the negative health effects of escalating training and dieting practices (Brenner, 2007; Carlsohn et al., 2011).

\section{A better competition through doping?}

In the previous sections, we argued that Red Queen effects would not be the rule as soon as doping would be allowed in sports. We presented what we believe is good evidence for the view that the effects of interventions to improve performance, be it training, nutrition, or (il)licit substance use, vary importantly between individuals and that a non-uniform stimulusresponse is the rule. This evidence invalidates the claim that pervasive doping would just shift the performance level uniformly up, leading to a zero-sum result. Obviously, this does not entail that the anti-doping stance needs to be given up. It just entails that one specific argument in the debate against allowing doping is shown to be flawed.

Some readers may find our critique of this particular argument compelling, while at the same time thinking that the empirical components of our argument can just as well be used in an argument against the relaxation of anti-doping. In a nutshell, such an anti-doping argument would go as follows: the doping ban is legitimate because allowing doping would result in winners who would have no chance if they wouldn't take doping. Doping use alters something essential about sports, and reduces the impact of exercise, skill and talent on the ranking. After all, the varying responses to pharmacology, can be expected to add to the variation in performance between individuals, thus leading to new and allegedly undeserving winners and new allegedly undeserving losers. According to philosophers such as Loland, this 
justifies a doping ban, since doping enhances performance in an artificial ('unnatural') way and also impacts the ranking (Lenk, 2013; Loland, 2018).

To a large extent, this anti-doping argument hinges on what counts as fairness in an athletic context, a contentious and much debated topic within the ethics of sports. Instead of reiterating all the existing arguments in this debate, we want to emphasize here that the interaction effects we discussed can also be used to boost fairness arguments in favour of a relaxation of current doping policies. This suggests that the link between varying athletic responses to pharmacological products and the fairness of athletic competitions is less straightforward than some may think, although it is obviously insufficient to demonstrate that the use of doping is unproblematic from a fairness perspective. But how can these arguments for a more liberal doping policy be boosted by the interaction effects we discussed?

First, there is the issue that most gene-environment interactions are not seen as a threat to fairness by those who consider interactions that involve substance use to lead to unfair outcomes. Indeed, today's elite playing field can be understood as bringing together individuals with a largely similar phenotype (i.e. sharing a similar level of performance), based on an unusual but given genetic background, brought to optimal expression in a certain environment (Issurin 2017). As long as the elite athletes do not use doping, their triumphs are not seen as unfair, even though they have little merit in much of their upbringing (their diet as a child, the climatological circumstances in which they developed, the affluence of their parents and home country, ...) or in their genes. Elite athletes are engaged in a continuous tweaking of their environmental exposure to obtain optimal responses (by means of training, nutrition, supplements, psychology, etc.) and performance has become a highly technological endeavour with many people involved in athlete preparation (coach, trainer, psychologist, nutritionist, physiologist, doctor, etc.). Adding doping as an additional means for tweaking could be seen as further adding variance to performance, an additional means that is not intrinsically less ethical than the often not much less 'artificial' means that are currently allowed.

Secondly, zero-tolerance does not lead to zero use, and we are highly sceptical that the 'war on doping' will ever be absolutely successful. Hence, even though the 'war on doping' is in full swing, as illustrated in the Introduction, doping is still being used by some winners who would never be a winner if all competitors abstained from doping. Moreover, one could even argue that there is some moral value in the fact that there are people who thanks to doping can 
be given the chance to compete with others. It would allow those with lesser base capital in one currency to exploit their larger base capital in (a hitherto forbidden) currency (Bonte, 2013). Because of the complexity of getting the tuning right, one could value this difficult endeavour as much as the hardship of training and optimal athlete support, giving it greater (aesthetical and/or ethical) value than the free but undeserved baseline talent. Seen in this way, doping could thus be thought to change something sport relevant in a way that is not necessarily negative.

\section{What about health?}

Fairness is one cornerstone of anti-doping arguments and policies, but health is arguably even more important. Hence, one obvious objection to our view is that relaxation of the doping ban will have dramatic health effects. Part of this issue was already addressed in the section on escalation. Still, even without an escalation of doping use, some may expect an increase of the health risk after the relaxation of the doping ban. We agree that this is a potential problem, but think that the risk depends to a large extent on how this relaxation is implemented. We discuss in this section how these relaxation measures and their effects on health are related to Red Queen effects.

Current anti-doping is prohibitionist and aimed at abstinence from a 'zero-tolerance' standpoint. What would be the effects of a policy change allowing doping within a health surveillance perspective? Without detailing the undoubtedly complex operationalisation, two different scenarios can be envisaged. First, a really open scenario can be envisioned, with no cut-off for any given intervention, leaving it to the athlete and their support team to decide on how to exploit any performance enhancement means. A closed scenario is also possible, with a cap to some (patho-)physiological effect, if beyond such a cut-off the health risk would be deemed excessive by some regulating instance. An example of an open scenario would be to take substances off the List such as meldonium (Negro et al., 2018). Athletes would be allowed to use meldonium at their discretion, but would be monitored to study the effects (good and bad). An example of a closed scenario would be to allow the use of EPO, but up to a maximum level of red-cell content of blood (i.e. haematocrit) of 50\%, a measure that was already introduced by the UCI (International Cycling Union) in 1997 on the basis of the idea that beyond $50 \%$ the health risk would increase irresponsibly (Neumayr et al., 2002). 
In the open model the varying frequencies and intensities of interventions chosen by the athletes, combined with the varying effects of such interventions between them, would exclude a Red Queen effect but instead add variance to the playing field. In the closed model, some Red Queen effects might be expected to the extent that e.g. an identical haematocrit (red blood cell content) would put all athletes on par for that specific variable, even though it can still be expected that the interaction with various other varying parameters would not eliminate overall variance of performance. Indeed, it is not obvious that for a given fixed level of some physiological parameter, e.g. haematocrit, or plasma growth hormone concentration, the overall physiological effect on performance would be identical between athletes. As we have explained earlier, the contrary is much more likely, since such parameters always interact with many others in a complicated dynamic.

Because of anti-doping measures, it has become very difficult to discover the performance and health effects of substances on the List, which also entails limitations for our approach. We have discussed the potential for doping runaway effects taking into account the (incomplete) empirical data available, making assumptions as realistic as possible. But the state of ignorance on the effects of doping, good and bad, that modern anti-doping has created, necessarily renders most arguments about the health risks of doping speculative. Still, we believe that the central claims of our paper rest on solid foundations. We contend that the argument that allowing doping would lead to a uniform increase in performance does not hold and should not be used anymore in arguments in favour of anti-doping policy. In sports, some limited Red Queen effects occur, but only up to the level that changes in behaviour of one's opponent (training, diet, supplements, doping) may lead to some level of adoption of such behaviour in the other athlete. But because of the varying effects to identical stimuli between athletes, the outcome will not level out, but instead will introduce further variance of performance. If the anti-doping rule would be relaxed, it would then be expected that the playing field would remain at least as dynamic as it is today, opening the way towards valuing the exploitation of baseline talent by all means, including doping.

For now anti-doping is asking for the contrary, more means in order to eradicate doping. The CEO of the world association of Olympians suggested to implant a chip into all athletes world-wide (Kelner, 2017). Extension of nootropic drug testing to coaches was proposed (Rodenberg \& Holden, 2017)This dynamic is akin to the advent of the general 'war on drugs', which was eventually proven to be a costly failure (Room \& Reuter, 2012). We find that 
modern anti-doping policy itself shows Red Queen like runaway dynamics in an 'endjustifies-the means' fashion. This policy is engaged in a spiralling 'war on doping' that does not and presumably cannot attain its goal, eradication of doping in elite and amateur sport. Ever more sophisticated means to detect doping use will lead to ever more sophisticated means to use doping. Ironically, such increasingly drastic measures are (sometimes) motivated by a fear that a relaxation of the anti-doping regulations would result in dramatic Red Queen effects. Of course, we do not deny that the current policy has had its partial successes. Yet, we do believe that less costly policies could be more successful, and that a successful policy should definitely not start from the wrong-headed assumption that allowing doping wouldn't alter the ranking, and would lead to an uncontrollable escalation of the use of unhealthy substances.

\section{Acknowledgments}

Nil

\section{Declaration of interest statement}

The authors declare no conflicts of interest.

\section{References}

Baar, K. (2014). Nutrition and the adaptation to endurance training. Sports Medicine (Auckland, N.Z.), 44(1), 5-12. https://doi.org/10.1007/s40279-014-0146-1

Baker, J., \& Wattie, N. (2018). Innate talent in sport: Separating myth from reality. Current Issues in Sport Science. https://doi.org/10.15203/ciss_2018.006

Bonte, P. (2013). Dignified doping: truly unthinkable? An existentialist critique of 'talentocracy' in sports (J. Tolleneer, Sigrid Sterckx, \& P. Bonte, Eds.; 2nd ed., Vol. 52, pp. 59-86). Springer Netherlands. https://doi.org/10.1007/978-94-007-5101-9_4

Bouchard, C., An, P., Rice, T., Skinner, J. S., Wilmore, J. H., Gagnon, J., Pérusse, L., Leon, A. S., \& Rao, D. C. (1999). Familial aggregation of VO(2max) response to exercise training: results from the HERITAGE Family Study. Journal of Applied Physiology, 87(3), 1003-1008. 
Breivik, G. (1992). Doping Games A Game Theoretical Exploration of Doping. International Review for the Sociology of Sport, 27(3), 235-253.

https://doi.org/10.1177/101269029202700303

Brenner, J. S. (2007). Overuse injuries, overtraining, and burnout in child and adolescent athletes. PEDIATRICS, 119(6), 1242-1245. https://doi.org/10.1542/peds.2007-0887

Brown, W. M. (1980). Ethics, drugs, and sport. Journal of the Philosophy of Sport, 7(7), 1523. https://doi.org/10.1080/00948705.1980.9714363

Carlsohn, A., Cassel, M., Linné, K., \& Mayer, F. (2011). How much is too much? A case report of nutritional supplement use of a high-performance athlete. The British Journal of Nutrition, 105(12), 1724-1728. https://doi.org/10.1017/s0007114510005556

Carroll, L. (1871). Through the Looking-Glass, and What Alice Found There. Macmillan.

Christiansen, A. V., \& Møller, V. (2007). Mål, medicin og moral: om eliteatleters opfattelse af sport, doping og fairplay. Syddansk Universitetsforlag.

Chwang, E. (2012). Why athletic doping should be banned. Journal of Applied Philosophy. https://doi.org/10.1111/j.1468-5930.2011.00547.x/pdf

Clark, B., Woolford, S. M., Eastwood, A., Sharpe, K., Barnes, P. G., \& Gore, C. J. (2017). Temporal changes in physiology and haematology in response to high- and micro-doses of recombinant human erythropoietin. Drug Testing and Analysis, 210 (Suppl 7), 649. https://doi.org/10.1002/dta.2176

Connor, J, \& Mazanov, J. (2009). Would you dope? A general population test of the Goldman dilemma. British Journal of Sports Medicine, 43(11), 871-872.

https://doi.org/10.1136/bjsm.2009.057596

Connor, James, Woolf, J., \& Mazanov, J. (2013). Would they dope? Revisiting the Goldman dilemma. British Journal of Sports Medicine, 47(11), 697-700. https://doi.org/10.1136/bjsports-2012-091826

Cosmides, L., \& Tooby, J. (2008). Can a General Deontic Logic Capture the Facts of Human Moral Reasoning? How the Mind Interprets Social Exchange Rules and Detects Cheaters. MIT Press. http://www.cep.ucsb.edu/papers/deonticCT2008.pdf

Danaher, J. (2012). Doping and competitive advantage: Chwang's argument (Part one). http://philosophicaldisquisitions.blogspot.ch/2012/10/doping-and-competitiveadvantage.html

Dawson, J., Thorogood, M., Marks, S.-A., Juszczak, E., Dodd, C., Lavis, G., \& Fitzpatrick, R. (2002). The prevalence of foot problems in older women: a cause for concern. Journal of Public Health Medicine, 24(2), 77-84.

Dimeo, P., \& Hunt, T. M. (2012). The doping of athletes in the former East Germany: A critical assessment of comparisons with Nazi medical experiments. International Review for the Sociology of Sport, 47(5), 581-593. https://doi.org/10.1177/1012690211403198 
Dimeo, P., \& Møller, V. (2018). The Anti-Doping Crisis in Sport. Routledge.

Dixon, N. (2008). Performance-enhancing drugs, paternalism, meritocracy, and harm to sport. Journal of Social Philosophy. https://doi.org/10.1111/j.1467-9833.2008.00423.x/pdf

Elbe, A.-M., \& Barkoukis, V. (2017). The psychology of doping. Current Opinion in Psychology, 16, 67-71. https://doi.org/10.1016/j.copsyc.2017.04.017

Faiss, R., Saugy, J., Zollinger, A., Robinson, N., Schuetz, F., Saugy, M., \& Garnier, P.-Y. (2020). Prevalence estimate of blood doping in elite track and field athletes during two major international events. Frontiers in Physiology, 11, 160.

https://doi.org/10.3389/fphys.2020.00160

Filipski, K. K., Pacanowski, M. A., Ramamoorthy, A., Feero, W. G., \& Freedman, A. N. (2016). Dosing recommendations for pharmacogenetic interactions related to drug metabolism. Pharmacogenetics and Genomics, 26(7), 334-339.

https://doi.org/10.1097/fpc.0000000000000220

Fincoeur, B., Frenger, M., \& Pitsch, W. (2013). Does one play with the athletes' health in the name of ethics? Performance Enhancement \& Health, 2(4), 182-193.

https://doi.org/10.1016/j.peh.2014.08.002

Frank, R. H. (2007). The economic naturalist : in search of explanations for everyday enigmas. New York : Basic Books.

Franke, W. W., \& Berendonk, B. (1997). Hormonal doping and androgenization of athletes: a secret program of the German Democratic Republic government. Clinical Chemistry, 43(7), 1262-1279. https://doi.org/10.1093/clinchem/43.7.1262

Gali, J. (1994). Keeping up with the Joneses: Consumption externalities, portfolio choice, and asset prices. Journal of Money, 26(1), 1. https://doi.org/10.2307/2078030

Goldman, B., \& Klatz, R. (1992). Death in the locker room. Elite Sports Medicine Pubns.

Grgic, J., Grgic, I., Pickering, C., Schoenfeld, B. J., Bishop, D. J., \& Pedisic, Z. (2019). Wake up and smell the coffee: caffeine supplementation and exercise performance-an umbrella review of 21 published meta-analyses. British Journal of Sports Medicine, bjsports-2018100278. https://doi.org/10.1136/bjsports-2018-100278

Hardeman, M., Alexy, T., Brouwer, B., Connes, P., Jung, F., Kuipers, H., \& Baskurt, O. K. (2014). EPO or PlacEPO? Science versus practical experience: panel discussion on efficacy of erythropoetin in improving performance. Biorheology, 51(2-3), 83-90. https://doi.org/10.3233/bir-140655

Heuberger, J. A. A. C., \& Cohen, A. F. (2019). Review of WADA prohibited substances: limited evidence for performance-enhancing effects. Sports Medicine (Auckland, N.Z.), 49(4), 525-539. https://doi.org/10.1007/s40279-018-1014-1

Heuberger, J. A. A. C., Tervaert, J. M. C., Schepers, F. M. L., Vliegenthart, A. D. B., Rotmans, J. I., Daniels, J. M. A., Burggraaf, J., \& Cohen, A. F. (2013). Erythropoietin 
doping in cycling: lack of evidence for efficacy and... - PubMed - NCBI. British Journal of Clinical Pharmacology, 75(6), 1406-1421. https://doi.org/10.1111/bcp.12034

Hew-Butler, T., Loi, V., Pani, A., \& Rosner, M. H. (2017). Exercise-associated hyponatremia: 2017 update. Frontiers in Medicine, 4(3), 21. https://doi.org/10.3389/fmed.2017.00021

Hon, O. de, Kuipers, H., \& Bottenburg, M. van. (2015). Prevalence of doping use in elite sports: a review of numbers and methods. Sports Medicine (Auckland, N.Z.), 45(1), 57-69. https://doi.org/10.1007/s40279-014-0247-x

Issurin, V. B. (2017). Evidence-based prerequisites and precursors of athletic talent: a review. Sports Medicine (Auckland, N.Z.), 47(10), 1993-2010. https://doi.org/10.1007/s40279017-0740-0

Jolls, C., Sunstein, C. R., \& Thaler, R. (1998). A behavioral approach to law and economics. Stanford Law Review, 50(5), 1471. https://doi.org/10.2307/1229304

Joyner, M. J., \& Lundby, C. (2018). Concepts about VO2max and trainability are context dependent. Exercise and Sport Sciences Reviews, 46(3), 138-143.

https://doi.org/10.1249/jes.0000000000000150

Karila, T. A. M., Karjalainen, J. E., Mäntysaari, M. J., Viitasalo, M. T., \& Seppälä, T. A. (2003). Anabolic androgenic steroids produce dose-dependent increase in left ventricular mass in power athletes, and this effect is potentiated by concomitant use of growth hormone. International Journal of Sports Medicine, 24(5), 337-343.

https://doi.org/10.1055/s-2003-40702

Kelner, M. (2017, October 10). Call for athletes to be fitted with microchips in fight against drug cheats. The Guardian. https://www.theguardian.com/sport/2017/oct/10/call-forathletes-to-be-fitted-with-microchips-fight-against-drug-cheats

Kruse, P., Ladefoged, J., Nielsen, U., Paulev, P. E., \& Sorensen, J. P. (1986). Beta-blockade used in precision sports: effect on pistol shooting performance. Journal of Applied Physiology, 61(2), 417-420. https://doi.org/10.1152/jappl.1986.61.2.417

Lenk, C. (2013). Is human enhancement unnatural and would this be an ethical problem? In J Tolleneer, S. Sterckx, \& P. Bonte (Eds.), Athletic Enhancement, Human Nature and Ethics. (Vol. 52, pp. 45-57). Springer. https://doi.org/10.1007/978-94-007-5101-9_3

Lintermans, A., Neven, P., \& Paridaens, R. (2011). Drug safety evaluation of exemestane. Expert Opinion on Drug Safety, 10(3), 473-487. https://doi.org/10.1517/14740338.2011.567264

Loland, S. (2009). The Ethics of Performance-Enhancing Technology in Sport. Journal of the Philosophy of Sport, 36(2), 152-161. https://doi.org/10.1080/00948705.2009.9714754

Loland, S. (2018). Performance-enhancing drugs, sport, and the ideal of natural athletic performance. The American Journal of Bioethics, 18(6), 8-15.

https://doi.org/10.1080/15265161.2018.1459934 
López, B. (2013). Creating fear: the 'doping deaths', risk communication and the anti-doping campaign. International Journal of Sport Policy and Politics, 1-13.

https://doi.org/10.1080/19406940.2013.773359

López, B. (2016). From needle phobia to doping phobia: Can the fear of injections help us understand anti-dopism? Drugs: Education, Prevention, and Policy, 24(3), 314-320. https://doi.org/10.1080/09687637.2016.1266299

Martins, H. (2018). The Technocene.

McVeigh, J., \& Begley, E. (2016). Anabolic steroids in the UK: an increasing issue for public health. Drugs: Education, Prevention, and Policy, 24(3), 278-285. https://doi.org/10.1080/09687637.2016.1245713

Millet, G. P., Chapman, R. F., Girard, O., \& Brocherie, F. (2019). Is live high-train low altitude training relevant for elite athletes? Flawed analysis from inaccurate data. British Journal of Sports Medicine, 53(15), 923-925. https://doi.org/10.1136/bjsports-2017098083

Milot, L. (2014). Ignorance, harm, and the regulation of performance-enhancing substances. Harvard Journal of Sports and Entertainment Law, 91, 91-146. https://doi.org/10.1037/e603962013-065

Møller, V. (2005). Knud Enemark Jensen's death during the 1960 Rome Olympics: a search for truth? Sport in History, 25(3), 452-471. https://doi.org/10.1080/17460260500396319

Moran, C. N., \& Pitsiladis, Y. P. (2016). Tour de France champions born or made: where do we take the genetics of performance? Journal of Sports Sciences, 35(14), 1411-1419. https://doi.org/10.1080/02640414.2016.1215494

Moston, S., \& Engelberg, T. (2016). Detecting Doping in Sport. Taylor \& Francis.

Negro, M., Marzullo, N., Caso, F., Calanni, L., \& D’Antona, G. (2018). Opinion paper: scientific, philosophical and legal consideration of doping in sports. European Journal of Applied Physiology, 118(4), 729-736. https://doi.org/10.1007/s00421-018-3821-3

Neumayr, G., Pfister, R., Mitterbauer, G., Gaenzer, H., Joannidis, M., Eibl, G., \& Hoertnagl, H. (2002). Short-term effects of prolonged strenuous endurance exercise on the level of haematocrit in amateur cyclists. Int J Sports Med, 23(3), 158-161.

https://doi.org/10.1055/s-2002-23169

Petróczi, A., Mazanov, J., Nepusz, T., Backhouse, S. H., \& Naughton, D. P. (2008). Comfort in big numbers: Does over-estimation of doping prevalence in others indicate selfinvolvement? Journal of Occupational Medicine and Toxicology (London, England), 3(1), 19. https://doi.org/10.1186/1745-6673-3-19

Pigeyre, M., Yazdi, F. T., Kaur, Y., \& Meyre, D. (2016). Recent progress in genetics, epigenetics and metagenomics unveils the pathophysiology of human obesity. Clinical Science (London, England: 1979), 130(12), 943-986. https://doi.org/10.1042/cs20160136 
Pluim, B. (2008). A doping sinner is not always a cheat. British Journal of Sports Medicine, $42(7), 549-550$.

Ring, C., Kavussanu, M., Simms, M., \& Mazanov, J. (2017). Effects of situational costs and benefits on projected doping likelihood. Psychology of Sport and Exercise. https://doi.org/10.1016/j.psychsport.2017.09.012

Rodenberg, R. M., \& Holden, J. T. (2017). Cognition enhancing drugs ('nootropics'): time to include coaches and team executives in doping tests? British Journal of Sports Medicine, 51(18), 1316-1316. https://doi.org/10.1136/bjsports-2015-095474

Room, R., \& Reuter, P. (2012). How well do international drug conventions protect public health? The Lancet, 379(9810), 84-91. https://doi.org/10.1016/s0140-6736(11)61423-2

Rubinstein, A. (2007). Afterword (p. 634).

Sanchis-Gomar, F., Pareja-Galeano, H., Rodriguez-Marroyo, J. A., Koning, J. J. de, Lucia, A., \& Foster, C. (2016). Olympic Genes on the Podium? International Journal of Sports Physiology and Performance, 11(7), 973-974. https://doi.org/10.1123/ijspp.2016-0421

Santos, L. R., \& Rosati, A. G. (2015). The evolutionary roots of human decision making. Dx.Doi.Org, 66(1), 321-347. https://doi.org/10.1146/annurev-psych-010814-015310

Schneider, A. J., \& Butcher, R. R. (1993). Why Olympic athletes should avoid the use and seek the elimination of performance-enhancing substances and practices from the Olympic Games. Journal of the Philosophy of Sport, 20(1), 64-81. https://doi.org/10.1080/00948705.1993.9714504

Shermer, M. (2008). The doping dilemma. Scientific American, 298(4), 82-89.

Siebenmann, C., Robach, P., Jacobs, R. A., Rasmussen, P., Nordsborg, N., Diaz, V., Zaslawski, C., Olsen, N. V., Maggiorini, M., \& Lundby, C. (2012). "Live high-train low" using normobaric hypoxia: a double-blinded, placebo-controlled study. Journal of Applied Physiology, 112(1), 106-117. https://doi.org/10.1152/japplphysiol.00388.2011

Simon, R. L. (1984). Good competition and drug-enhanced performance. Journal of the Philosophy of Sport, 11(1), 6-13. https://doi.org/10.1080/00948705.1984.9714408

Sinex, J. A., \& Chapman, R. F. (2015). Hypoxic training methods for improving endurance exercise performance. Journal of Sport and Health Science, 4(4), 325-332. https://doi.org/10.1016/j.jshs.2015.07.005

Smith, C. (2016). Tour du dopage: Confessions of doping professional cyclists in a modern work environment. International Review for the Sociology of Sport, 52(1), 97-111. https://doi.org/10.1177/1012690215572855

Strulik, H. (2012). Riding high: success in sports and the rise of doping cultures. The Scandinavian Journal of Economics, 114(2), 539-574. https://doi.org/10.1111/j.14679442.2012.01698.x 
Teger, A. I. (2017). Too Much Invested to Quit. Elsevier.

Timmons, J. A., Knudsen, S., Rankinen, T., Koch, L. G., Sarzynski, M., Jensen, T., Keller, P., Scheele, C., Vollaard, N. B. J., Nielsen, S., Akerstrom, T., MacDougald, O. A., Jansson, E., Greenhaff, P. L., Tarnopolsky, M. A., Loon, L. J. C. van, Pedersen, B. K., Sundberg, C. J., Wahlestedt, C., ... Bouchard, C. (2010). Using molecular classification to predict gains in maximal aerobic capacity following endurance exercise training in humans. Journal of Applied Physiology, 108(6), 1487-1496. https://doi.org/10.1152/japplphysiol.01295.2009

Tucker, R., \& Collins, M. (2012). What makes champions? A review of the relative contribution of genes and training to sporting success. British Journal of Sports Medicine, 46(8), 555-561. https://doi.org/10.1136/bjsports-2011-090548

Ulrich, R., Pope, H. G., Cléret, L., Petróczi, A., Nepusz, T., Schaffer, J., Kanayama, G., Comstock, R. D., \& Simon, P. (2017). Doping in two elite athletics competitions assessed by randomized-response surveys. Sports Medicine (Auckland, N.Z.), 48(1), 211-219. https://doi.org/10.1007/s40279-017-0765-4

Valen, L. V. (1973). A new evolutionary law. Evolutionary Theory, 1, 1-30.

Warden, S. J. (2015). Prophylactic Use of NSAIDs by Athletes: A Risk/Benefit Assessment. The Physician and Sportsmedicine, 38(1), 132-138. https://doi.org/10.3810/psm.2010.04.1770

Worman, C. O., \& Kimbrell, T. (2008). Getting to the hart of the matter: did antlers truly cause the extinction of the Irish elk? Oikos, 117(9), 1397-1405. https://doi.org/10.1111/j.0030-1299.2008.16608.x

Wright, D. F. B., Winter, H. R., \& Duffull, S. B. (2011). Understanding the time course of pharmacological effect: a PKPD approach. British Journal of Clinical Pharmacology, 71(6), 815-823. https://doi.org/10.1111/j.1365-2125.2011.03925.x 